Jewish people preserved a distinctive culture throughout two thousand years of diaspora, and those Jews who wish to do so can now participate in building and preserving a society based on that culture. There is continuing validity in the traditional Indian culture, in Islamic culture, in Buddhist culture, in traditional Chinese culture, in sub-Sahara African culture. Surely, diversity will increase as new potentialities of life and nature are discovered by science and made possible by technology. ${ }^{39}$

The alternative way to avoid the universal triumph of totalitarianism and nuclear Armageddon is to pursue the more modest goal of clusters of national societies based upon a variety of cultures. This goal follows from acceptance of cultural diversity, instead of cultural universality, as the basis of international law. Every culture grasps some part, but not the whole, of the rich and complex meaning of existence. It should be the basic principle of international law that persons who share fundamental beliefs about the world and human nature have the right to organize and govern their activities in accordance with the social implications of those beliefs; but they do not have the right to impose the beliefs or the social system upon others. In a world characterized by clusters of national societies based on a variety of cultures, peace and security would depend upon an international law of cultural tolerance and negotiated agreements based on mutual advantage.

GRAY L. DORSEY*

\title{
The Dorsey Comment: A Modest Retrogression
}

It seems to me, with all respect, that the Comment by Professor Dorsey exhibits a minimum understanding both of the contemporary world and of the theory and intellectual procedures recommended by Harold Lasswell and his associates for inquiry about the role of international law in that world. Certainly Professor Dorsey and Lasswell and associates observe very different worlds, have very different conceptions of international law, and recommend very different methods of inquiry. It is not clear that Professor Dorsey is constrained by empirical observation and modern scientific methods of inquiry.

For Professor Dorsey, as developed in this Comment and in his book, ${ }^{1}$ there is no global community of humankind in the sense of an interdetermination and interdependence in the shaping and sharing of values. All he can observe is an aggregation of nation-states, each characterized by a unique, impermeable "culture" that stops short at national boundaries. "The nation-state system," he explains, "is a cultural system." "This

\footnotetext{
39 This paragraph is quoted from my book, $i d$. at 83-84.

* Charles Nagel Professor of Jurisprudence and International Law, School of Law, Washington University at St. Louis; President (1975-1979), International Association for Philosophy of Law and Social Philosophy.

${ }^{1} G$. Dorsey, Beyond the United Nations: Changing Discourse in International PoLITICS AND LAW (1986) [hereinafter Book].
} 
means," he adds, "that the members have much the same beliefs about the world, human nature, what is worth having, how to know, who can know, and have much the same values and purposes."2 He nowhere explains why beliefs, natures, values and purposes cannot transcend the inherited, and continuously changing, boundaries of nation-states. According to Dorsey, the individual human being and his many associations other than the nation-state cannot act directly in world social process; the nation-state must act for them. ${ }^{3}$ It would be treason for the individual to act, since in violation of "obligation" to the nation-state. ${ }^{4}$ For some incredible reason, for individuals to act directly in world social process would be to reject "the basic proposition of the Universal Declaration of Human Rights that '[a]ll human beings are . . . endowed with reason and conscience . . . ." It seems that rational human beings can only organize in exclusive communities with people who think and talk exactly as they do; hence, people "enclowed with reason" must opt for tribal and smaller units and cannot participate in a transnational social process. While he offers no map of a comprehensive, global process of effective power, Professor Dorsey does repeatedly insist that the bases of effective power are to be found in assets irretrievably locked within the boundaries of nation-states and that it is futile to try to change the situation. ${ }^{6}$ The conception of international law projected by Professor Dorsey is that of the positivist paradigm: a body of rules that regulates the interactions of, expresses the "sovereignty" of, nation-states, without applying directly to the activities of individual human beings and their various associations. In his book he states concisely: "International Law . . . is the body of rules for distributing among states the authority to govern human activities."7 A contrasting conception of transnational expectations and decisions about authority and control, relating to the activities of all participants in a global community process, would be dangerously conducive of a destructive universality.

Lasswell and associates, both in the article under attack by Professor Dorsey and numerous other monographs and books, ${ }^{8}$ have observed, and sought to map, a very different world. They can observe that there is in fact, wholly apart from their "definitions," a comprehensive earth-space community of the whole of humankind, transcending all national boundaries, in the sense of interdetermination and interdependence in the shaping and sharing of all values, even that of survival. ${ }^{9}$ The participants in this most comprehensive community process they observe to be, not merely nation-states,

\footnotetext{
${ }^{2}$ Book at 31 .

"We are tempted to ask: Did anyone ever see a "nation-state" "coming and going" or "buying and selling" or "looking and listening"? Dorsey, The McDougal-Lasswell Proposal to Build a World Public Order, supra at p. 41, 42 [hereinafter Comment].

${ }^{4}$ Id. at 43 .

${ }^{6}$ Id. at 47.

5 Id. at 42.

8 The citations offered by Professor Dorsey are ample.

${ }^{9}$ Expansion and documentation of the description offered in this paragraph may be found in M. S. McDougal \& W. M. Reisman, International Law Essays (1981), and M. S. McDougal, H. Lasswell \& L. Chen, Human Rights and Worid Public Order (1980).
} 
but the individual human beings who create nation-states and all their other groupings and associations, such as international governmental organizations, political parties, pressure groups and private associations specialized to all demanded values. They discern also, as a most important component within the comprehensive community process, an ongoing process of effective power, equally global in reach, in which decisions are in fact taken and enforced by severe deprivations or high indulgences, irrespective of the wishes of particular participants. ${ }^{10}$ The bases of power at the disposal of participants in this process of effective power, they note, are not restricted to physical resources hermetically sealed within nation-states; resources are important only as potential values, and in a world in which individuals and goods are in constant movement, reciprocities and retaliations with respect to all values become bases of power. In addition, as science and technology advance on a global scale, enlightenment and skill, as well as conceptions of rectitude and responsibility, become of increasing significance.

Many of the decisions taken in the larger process of effective power, Lasswell and his associates further observe, are taken, not by sheer naked power or from convenience, but rather from perspectives of authority: these decisions are made by participants who are expected to make them, in accordance with policy criteria expected by community members, in established structures of authority, with enough bases in power to secure consequential control, and by prescribed procedures. Upon close examination, this flow of authoritative decision within the larger, global community can be seen, as within lesser communities, to be composed of two distinct, though interrelated, kinds of decisions: "constitutive" decisions, which establish and maintain the most comprehensive process of authoritative decision, and "public order" decisions, made within the constitutive process, in regulation of the larger community's different value processes. The constitutive decisions are those that establish who the authoritative decision makers are, what fundamental policies they are to apply to what problems, the arenas of their interaction, the bases of power at their disposal, the procedures that they may employ, and the various activities or functions by which law is made and applied. The public order decisions are those that determine how resources are allocated and employed, how wealth is produced and distributed, how human rights are promoted and protected, how enlightenment is encouraged or blighted, how health is fostered or neglected, and so on. The conception of international law recommended by Lasswell and his associates makes reference to the totality of this flow of authoritative decision, both constitutive and public order, within the global community: international law is most realistically regarded, after the model of the American Legal Realists with respect to the law of any community, as that comprehensive process of authoritative decision by which the members

\footnotetext{
${ }^{10}$ Extended description of the global process of effective power is offered by McDougal, Reisman \& Willard, The World Process of Effective Power: The Global War System, in POWER AND POlicY IN QUEST OF LAW: ESSAYS IN HONOR OF EUGENE Victor Rostow 353 (M. S. McDougal \& W. M. Reisman eds. 1985).
} 
of the larger community of humankind seek to clarify and secure their common interests in the shaping and sharing of all values. The inherited body of rules, described as international law in the positivist frame, with its abundant complementarities, ambiguities and incompletions, has meaning only insofar as it refers to past decision or to the guidance, not command, of future decision.

For detailed inquiry about the role of law (the making of decisions and their consequences) in the larger global community of humankind, Lasswell and associates recommend both a comprehensive, careful mapping of that process, including its components in effective power and authoritative decision, and the employment of a number of distinct, though interrelated, intellectual procedures. ${ }^{11}$ They recognize that the making or recommending of decisions, rational by the criteria of common interest, requires that the decision maker or scholar be able to formulate problems in terms of the values at stake, both for the immediate parties and for the various communities of which they are members, and to explore the largest possible context of such problems for identifying and testing options in decision in terms of their value consequences for the different parties and communities. Hence, for the mapping of community processes, both comprehensive and lesser, they proffer theory for description in terms both of component value processes (power, respect, enlightenment, wealth, well-being, skill, affection, rectitude) and of institutional practices specialized to each value (participation, perspectives, situations, base values, strategies, outcomes), which can be made as comprehensive and as precise as any particular problem may require. ${ }^{12}$ From such description, it may be seen that the notion of impermeable national cultures is a delusion: different people may pursue the same values, achieve the same value consequences, by many different institutional practices.

For guidance in making or recommending particular decisions, Lasswell and associates recommend the explicit postulation, rather than derivation or assumption, of a fundamental community commitment to the historic values of human dignity, as contemporaneously expressed in the emerging global bill of human rights (the Universal Declaration of Human Rights, the many ancillary conventions and decisions) and many national constitutions and decisions. ${ }^{13}$ It should require no elaboration that there is nothing metaphysical or transempirical in the postulation of a community commitment in terms that make a designative reference to the interactions of individual human beings in the shaping and sharing of particular values. ${ }^{14}$ The more

\footnotetext{
11 These recommendations are stated in some detail in the article attacked by Professor Dorsey. See also the citations referred to supra note 8.

12 The relevant global processes are described in these terms in great detail in M. S. MCDOUgal, H. LASSwELl \& L. CHEN, supra note 9.

${ }^{15}$ In chapter 4 of McDougal, Lasswell, and Chen, id., we document that this postulation is rapidly becoming customary international law. In later chapters of the book, we illustrate how the postulated policies may be, and are being, applied to a variety of particular problems.

${ }^{14}$ In his Comment, supra at p. 48, Professor Dorsey refers to our postulated goal of "egalitarian-democratic human dignity" as having a "nonempirical premise." A postulation that
} 
specific intellectual procedures recommended by Lasswell and associates as manifestly relevant, even indispensable, to the making or recommending of decisions rational by the criteria of common interest may briefly be recapitulated.

First, the clarification of goal. A provisional relation of postulated community commitments and authoritative prescriptions to particular problems in projection of possible outcomes in decision. Such possible outcomes are provisional since they require testing by the other relevant intellectual procedures.

Second, description of trend. The examination of past trends in decision upon problems raising comparable policies for whatever wisdom they may yield about options in decision and the value consequences of different options. Note may be taken not only of immediate consequences but of aggregate consequences through time.

Third, analysis of conditioning factors. An exploration of the environmental and predispositional factors affecting past decisions upon comparable problems and of the constraints that such factors have imposed upon the choice of options.

Fourth, projection of future developments. The projection of value goals, trends and conditions into the future, considering how probable changes in conditions may affect both options in decision and the value consequences of different options in decision.

Fifth, invention and consideration of policy alternatives. The identifying and the making of a culminating commitment that best expresses the common interests in postulated values of the parties to a problem and of the communities of which they are members. For some problems in some contexts it may be necessary to reorganize the framework of interaction between the parties, in a reformulation of the problem, in order to achieve an appropriate integration of all interests.

Professor Dorsey offers no systematic statement of descriptive theory or intellectual procedures. The key concept in the structure of his argument is that of "culture," which is left highly mystical. ${ }^{15}$ All we can learn is that it has many national forms, sometimes has "nonempirical" premises that seep into consciousness, and is very difficult, if not impossible, to change. He makes no explicit postulation of a community commitment to goal values and derides the suggestion that "an egalitarian-democratic distribution of values" is an "essential meaning" of human dignity. ${ }^{16}$ The promotion of the values of human dignity on a transnational scale he finds as dangerous to

makes a designative reference to interactions between human beings in the shaping and sharing of values is scarcely nonempirical.

${ }^{15}$ Lasswell indicates some of the difficulties in describing culture, and the interrelations of culture and personality, in Person, Personality, Group, Culture, 2 Psychiarry 523 (1939). Professor Dorsey is confronted with especial difficulties because of the miraculous powers he attributes to culture. His conception bears some resemblance to the community "geist" of the historical jurists of the previous century.

16. Comment at 47. 
peace as the promotion of totalitarianism. ${ }^{17} \mathrm{He}$ indicates no particular intellectual procedures as especially relevant to inquiry about law in his world and mocks the specific tasks Lasswell and associates recommend as relevant, if not indispensable, to rational decision and recommendation in the common interest. ${ }^{18} \mathrm{He}$ suggests that the social sciences seek to be empirical but have limited predictive capabilities "because human actions are not determined by nature but by culture." 19 He finds difficulty in that "the currently dominant method of thought about human associations is concerned with empirical evidence of causal relations between antecedent and consequent events of human behavior" and in that questions of "right or wrong" are determined by "their practical consequences." ${ }^{20} \mathrm{He}$ suggests a preference for the methods of the Middle Ages when questions of right and wrong were determined "by moral philosophy, which reasoned deductively from assumed truths about the world and human nature."21 He asserts that "if the cultural basis of human action is not understood and respected, attempts to control human events beneficially, can be disastrous" ${ }^{22}$ and insists that the "failure to recognize the cultural basis of human action and association produces its most dangerous illusions in peace activism." ${ }^{23}$ It is most unhappy that Professor Dorsey gives us so few clues about how to recognize this all-important "cultural basis." Possibly, as Justice Stewart said of pornography, we can only know it when we see it.

It may be noted that the dangers dichotomized by Professor Dorsey at the beginning of his Comment, as between the triumph of totalitarianism and nuclear war, do not exhaust the possibilities. There is the further possibility of a continuing inadequate international legal system in which expectations of violence and anxiety remain high, crippling all productive activities and leaving the vast numbers of people already under totalitarian rule permanently denied opportunity for lives of human dignity. In his proposal that we "pursue the more modest goal of clusters of national societies based upon a variety of cultures" 24 and forgo the transnational promotion of the values of human dignity, Professor Dorsey would appear to opt for this third alternative. For many observers such a choice can represent only an anachronistic, defeatist nostalgia. It is a last cry, in a rapidly changing world, for national exclusivism and tribalism. People of different nations and cultures are, so it appears to be thought, unalterably different. The growth of heterogeneous systems with some degree of homogeneity is an illusion. The United States, for example, does not exist. Rational people, endowed with reason, are entirely selfish, enjoying no conception of common interest. They are unable to see that collaborative arrangements may be productive and enhance the values and security of both themselves and others. Such a perception is evidently alien to Professor Dorsey's conception of rational, reason-endowed people. His people do indeed operate in the Middle Ages.

\footnotetext{
${ }^{17}$ Id. at 50.

19 Book at 92.

${ }^{21}$ Id.

${ }^{23} I d$. at 96.
}

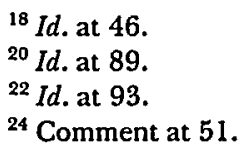


They build walls around the little pieces of the planet they think they control and dig moats beyond the walls. They are oblivious to the extraordinary interchange of values in the contemporary world and the inescapable interdeterminations and interdependences so created with respect to all values, including security. Each, within his own little nation-state, cultivates his own culture and resource environment while excluding all others from any of the values that he thinks he alone has created. The question is not whether this individual triumphs over totalitarianism. He must himself become increasingly totalitarian as he maintains a garrison state to protect what he regards as his. The relevant question is whether he can survive in a clump of clusters half-slave and half-free.

In the very article under attack by Professor Dorsey, Lasswell and I pointed out that the spokesmen of the totalitarian powers have the most to gain by the approach recommended by him. We wrote:

Strange as it may seem at first glance, the most convincing interpretation is that the existing imperfections of the system can be used by them [the spokesmen of the totalitarian powers] to help prevent further advances toward a world order with genuine measures of security. For it is in the name of such allegedly universal doctrines of international law as sovereignty, domestic jurisdiction, non-intervention, independence and equality - all of which appear to fortify claims to freedom from external obligation - that the case is made to resist the institutional reconstructions which are indispensable to security. ${ }^{25}$

We added: "It is high time that the community of scholars abandon a conception of their rôle in history whose principal effect is to condemn them to inaccuracy and futility." 26

Myres S. MCDougaL*

${ }^{25}$ McDougal \& Lasswell, The Identification and Appraisal of Diverse Systems of Public Order, 53 AJIL 1, 4 (1959).

${ }^{26}$ Id. at 28.

* Of the Board of Editors. 